Proceedings

\title{
Remote Sensing of Near-Real-Time Heavy Precipitation Using Observations from GPM and MFG over India and Nearby Oceanic Regions ${ }^{\dagger}$
}

\author{
Mohammd Rafiq * and Anoop Kumar Mishra \\ Centre for Remote Sensing and Geoinformatics, Sathyabama University, Chennai, Tamil Nadu, India; \\ daksha112@gmail.com \\ * Correspondence: emidamls6@gmail.com; Tel.: +91-946-918-3781 \\ + Presented at the 2nd International Electronic Conference on Remote Sensing, 22 March-5 April 2018; \\ Available online: https://sciforum.net/conference/ecrs-2.
}

Published: 23 March 2018

\begin{abstract}
This study deals with the integration of merging highly accurate precipitation estimates from the Global Precipitation Measurement (GPM) with sampling gap-free satellite observations from Meteosat 7 of the Meteosat First Generation (MFG) to develop a regional rainfall monitoring algorithm to monitor precipitation over India and nearby oceanic regions. For this purpose, we derived precipitation signatures from Meteosat observations to co-locate them against precipitation from GPM. A relationship was then established between rainfall and rainfall signature using observations from various rainy seasons. The relationship thus derived can be used to monitor precipitation over India and nearby oceanic regions. The performance of this technique was tested against rain gauges and global precipitation products including the Global Satellite Mapping of Precipitation (GSMaP), Climate Prediction Centre MORPHing (CMORPH), Precipitation Estimation from Remote Sensing Information using Artificial Neural Network (PERSIANN) and Integrated Multi-satellitE Retrievals for GPM (IMERG). A case study is presented here to examine the performance of the developed algorithm in monitoring heavy rainfall during the flood event in Tamil Nadu in 2015. This is the first attempt to use near-real-time observations from GPM and MFG to monitor heavy precipitation over the Indian region. Due to its finer resolution and near-real-time availability, this technique can be used to monitor near-real-time flash floods.
\end{abstract}

Keywords: precipitation estimation; NRT precipitation; flood; drought; convective clouds

\section{Introduction}

Near-real-time (NRT) precipitation information at fine resolutions is required to monitor flash floods. Unfortunately, the Indian regions have a poor density of ground-based rain gauges and radars. Moreover, usually rain gauge stations stop functioning during severe flood situations [1]. Flood events are associated with a large spatial and temporal variation of rainfall and hence continuous NRT, high-resolution, hourly satellite data is essential to monitor such events [2]. Such observations can be achieved by merging microwave precipitation estimates with rain signatures from geostationary satellites. Past research reports that cold observations from IR are associated with convective clouds and thus heavy precipitation [2,3]. In the past few decades, various satellite precipitation products have become widely available for users. These data sets integrate precipitation estimates and signatures from different sensors and satellites into a precipitation product. These data sets include the Tropical Rainfall Measuring Mission Mission (TRMM) Multisatellite Precipitation Analysis (TMPA) NRT product [4], the Global Satellite Mapping of Precipitation (GSMaP) [5,6], Climate Prediction Centre MORPHing (CMORPH) [7], Precipitation Estimation from Remote Sensing 
Information using Artificial Neural Networks (PERSIANN) [8], Hydro-Estimator (H-E) [9], and Integrated Multi-satellitE Retrievals for GPM (IMERG) [10]. Validation results show that most of these products produce large errors over the Indian region [2,3]. Mishra et al., [11] reported that the regional rain signatures derived for India outperform global rainfall signatures for their application over India. Few efforts have been made to monitor rainfall over India and nearby region through the synergistic use of multi-satellite sensors [3,12-15]. The availability of microwave measurements with broader swath and high frequency ice scattering channels from GPM provide a unique opportunity to merge accurate microwave rainfall information with infrared observations from Meteosat over India. The GPM Core Observatory measures precipitation using two sensors: the GPM Microwave Imager (GMI) and the Dual-Frequency Precipitation Radar (DPR). A recent preliminary study reports that rainfall estimates from DPR onboard GPM are closer to the gauge estimates than those from PR onboard TRMM [16].

In this study, we merged observations from the combined DPR and GMI with Meteosat to monitor near-real-time precipitation over the Indian region and the nearby oceans. The validations were performed using a rain-gauge-based product to test the accuracy of the present approach for its application in heavy rainfall cases.

\section{Data Used and Study Area}

For the present study, Meteosat 7 data from the Meteosat First Generation (MFG) was used. MFG provides images of the full Earth disc, and data for weather forecasts. Meteosat provides observations in the thermal infra-red (TIR) and water vapor (WV) absorption bands at half-hourly intervals, with a spatial resolution of $4 \mathrm{~km}$.Combined GMI-DPR-based rainfall from GPM was also used in this study. This product is described by Grecu et al. $[17,18]$. In order to test the performance of the present technique, rainfall estimates from GSMaP, CMORPH, PERSIANN and IMERG were also used. Rain gauge observations from AWS were used to validate the performance of the present technique. The study area spans from $10^{\circ} \mathrm{S}-40^{\circ} \mathrm{N}$ to $60^{\circ} \mathrm{E}-100^{\circ} \mathrm{E}$.

\section{Methodology}

Multi-frequency observations at multiple channels from Meteosat were used to filter out false rainfall signatures. We used a cloud classification scheme devised by Roca et al. [19]) and adopted by Mishra et al. [3] to delineate non-rainy thin cirrus clouds. If the brightness temperature in the IR band (IRTB) $\geq 270 \mathrm{~K}$ and cloudy and the brightness temperature in the WV band (WVTB) $\leq 246 \mathrm{~K}$, then the pixel represented thin cirrus clouds and was screened out. During the day, the cloud microphysical properties at near IR observations and visible reflectance were used to screen rainy pixels following the criteria used by Rosenfeld and Gutman [20].

It was reported by Mishra et al. [3] that a few cirrus clouds were still undetected even after applying threshold-based cloud classification. In order to screen out the non-rainy cirrus clouds, we used the criteria developed by Adler and Negri [21] as a second step. Following this approach, a slope (S) and a temperature gradient (Gt) were estimated for each local temperature minimum (using brightness temperature (IRTB) at $11.5 \mu \mathrm{m}$ ). The terms Gt and $S$ are computed by Equations (1) and (2), respectively:

$$
\begin{aligned}
\text { Gt }=\text { IRTBavg }- \text { IRTBmin } \\
\mathrm{S}=0.568(\text { IRTBmin }-217)
\end{aligned}
$$

where IRTBmin is the local minimum; and as in Adler and Negri (1988), IRTBavg is the mean temperature. It may be noted that the local minima is computed for an area covered by 6 IR pixels (4 pixels along the scan and 2 pixels across the scan). A large Gt shows convective clouds and a small Gt represents a weak gradient and shows the presence of cirrus clouds within the window. All pixels with a Gt less than $S$ are classified as cirrus clouds and therefore are rejected as non-raining clouds.

Following the filtering out of erroneous clouds, IRTB were co-located against the combined GMI-DPR rainfall within 15 min of difference, in which the auto covariance function of rainfall was 
reduced to about 0.9 [22]. "Fifteen minutes of difference" is the maximum allowed time difference for simultaneous observations of GPM and Meteosat. A data re-sampling scheme was used to minimize the co-location uncertainty due to differences in resolution. For the co-location process, rainfall from GPM is remapped in a $0.1^{\circ}$ grid. Then, IR-observations from Meteosat were also remapped in a $0.1^{\circ}$ grid. The co-location process is similar to that described in Mishra et al. [3]. It may be noted that the present algorithm aims to estimate rainfall at the $0.1^{\circ}$ grid level.

For the purpose of co-location, 18,654 data points (re-sampled in a $0.1^{\circ}$ grid)were used, consisting of rain events during the years 2015 and 2016. Of 18,654 data points, 6642 were rainy pixels while 12,012 were non-rainy pixels. A total of 12,862 data points were used for the independent validation purpose. This shows that out of $31,515(18,654+12,862)$ data points $41 \%$ of total data points were used for the validation purpose.

The relationship between IRTB and rainfall is shown in Figure 1a. It can be seen that heavy rainfall events are associated with a cold brightness temperature, representing convective and deep convective clouds. Good correlation between rainfall and IRTB may be attributed to the inclusion of a good number of heavy rainfall events (convective) and the delineation of erroneous cirrus clouds.
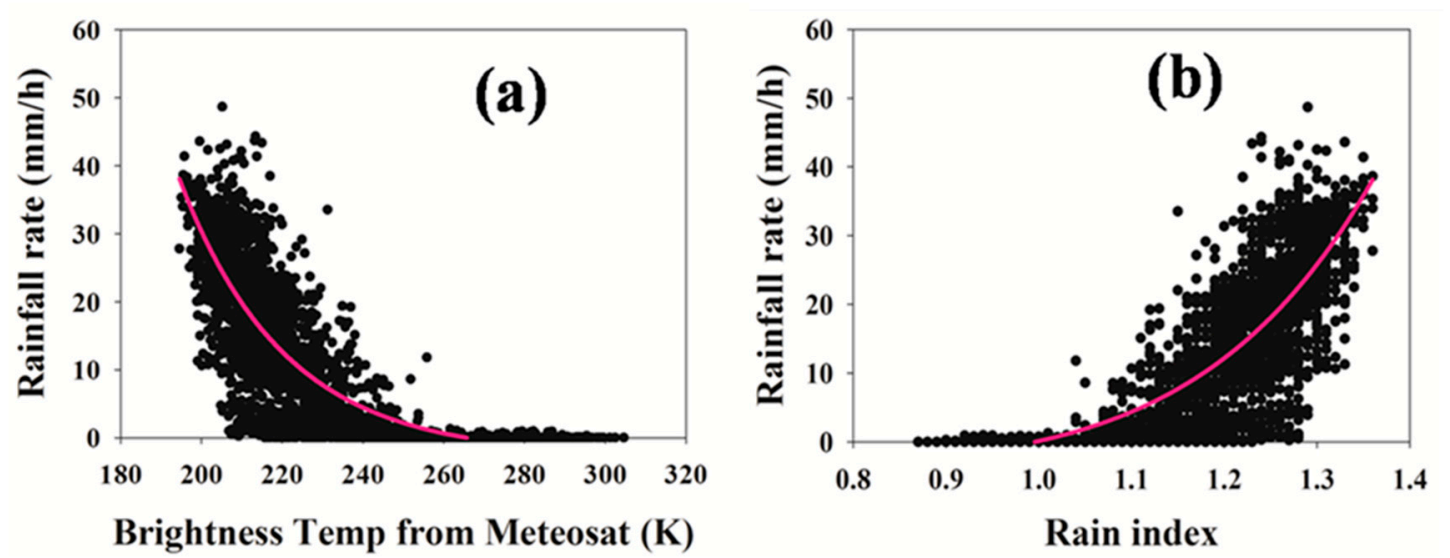

Brightness Temp from Meteosat (K)

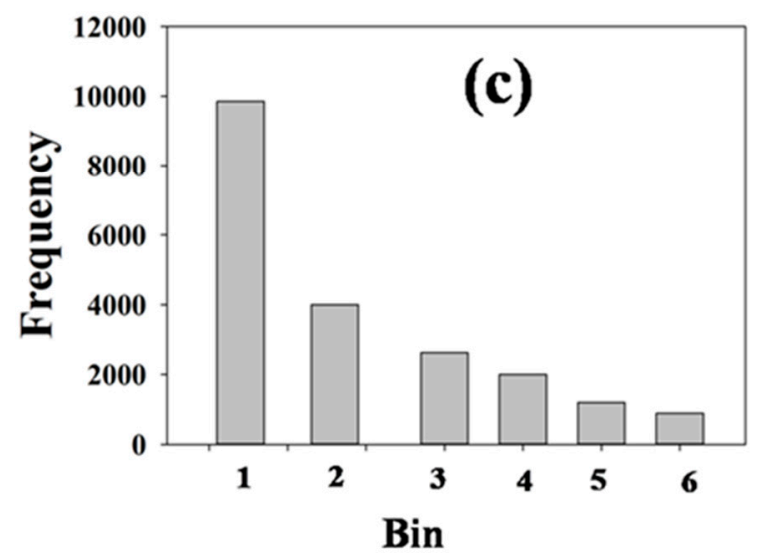

Figure 1. Scatter plot between rainfall rate (from GPM) and (a) brightness temperature (from Meteosat) (b) and rain index; (c) histogram of frequency at different bins. Precipitation bins are defined as $2 \mathrm{~mm} / \mathrm{h}, 8 \mathrm{~mm} / \mathrm{h}, 15 \mathrm{~mm} / \mathrm{h}, 20 \mathrm{~mm} / \mathrm{h}, 25 \mathrm{~mm} / \mathrm{h}$ and $30 \mathrm{~mm} / \mathrm{h}$ (selected bin sizes set to accommodate the entire rainfall spectrum). Figure source (Mishra and Rafiq 2017, Dynamics of Atmospheres and Oceans). 
A non rainy threshold of about $264 \mathrm{~K}$ (IRTB0) is observed. We define rain index (RI) as follows:

$$
\mathrm{RI}=(\mathrm{IRTB} 0 / \mathrm{IRTB})
$$

An IRTB $>264 \mathrm{~K}$ indicates a RI $<1$ and is representative of non-rainy cases. Higher values of RI show heavy rainfall associated with intense rainy systems. RIs thus estimated are collocated against GMI-DPR rainfall to establish a regression equation between them (Figure 1b).We classified the precipitation spectrum (and corresponding brightness temperature and rain index) into six bins. These precipitation bins were defined as $2 \mathrm{~mm} / \mathrm{h}, 8 \mathrm{~mm} / \mathrm{h}, 15 \mathrm{~mm} / \mathrm{h}, 20 \mathrm{~mm} / \mathrm{h}, 25 \mathrm{~mm} / \mathrm{h}$ and $30 \mathrm{~mm} / \mathrm{h}$. Figure 1c shows a histogram of the number of occurrences of these bins.

It can be seen from Figure $1 \mathrm{~b}$ that there are large scatters between rainfall and rain index, which is attributed to various factors ranging from the uncertainty caused by the use of different sensors from different platforms (difference in viewing geometry from MFG and GPM), collocation errors, poor relationships between warm rain (light rain) and IR brightness temperature, and a weak characterization of orographic rain from the IR signature.

The following equation was established between the RI and rain rate:

$$
\text { Rain rate }(\mathrm{mm} / \mathrm{h})=\mathrm{a}+(\mathrm{b} \times \mathrm{RIc})
$$

where $\mathrm{a}=-3.79(\mathrm{~mm} / \mathrm{h}), \mathrm{b}=4.55(\mathrm{~mm} / \mathrm{h})$, and $\mathrm{c}=6.68$.

The coefficients ' $a$ ' and ' $b$ ' essentially characterize the relationship between the rain rate and rain index, allowing for variation caused by scatter in the rain rate and rain index. This relationship exhibits a correlation coefficient (CC) of 0.83 , and a standard error of estimates of $6.20 \mathrm{~mm} / \mathrm{h}$. This relationship confirms the power law relationship between the rain index and rainfall as observed by past research $[2,13]$. The RI ranged from 0.86 to 1.37 . It can be concluded from Figure $1 \mathrm{~b}$ that a RI $>$ 1.3 indicates heavy rainfall cases of $25 \mathrm{~mm} / \mathrm{h}$ and above (observation of line of fit indicated by pink color in Figure 1b).

\section{Results and Discussion}

The aim of the present algorithm was to monitor near-real-time heavy rain systems. The performance of this technique was tested by applying it to a number of flood events. We used rain gauge observations from Tamil Nadu for the validation of the present algorithm during a flood event in Tamil Nadu in 2015.

Tamil Nadu witnessed heavy flooding during November-December in 2015. A case study was performed for the Tambram region $\left(12.933^{\circ} \mathrm{N}, 80.216^{\circ} \mathrm{E}\right)$ of Kancheepuram district in Tamil Nadu during the severe flood events of 2015 . For this purpose, daily rainfall data from the regional meteorological centre, Chennai, was used. Rain-gauge-based daily rainfall was estimated by accumulating rainfall for $24 \mathrm{~h}$ ending at 08:30 IST (03:00 GMT). For this validation purpose, hourly rainfall data from IMERG, GSMaP_NRT, CMORPH_RAW, PERSIANN were accumulated, starting at 03:00 GMT of the previous day and ending at 03:00 GMT of the day named.

It can be seenin the figure 2 that the satellite estimates underestimated the heavy rainfall. Among the satellite estimates, the present technique was the closest to the rain gauge observations in monitoring heavy rainfall. 


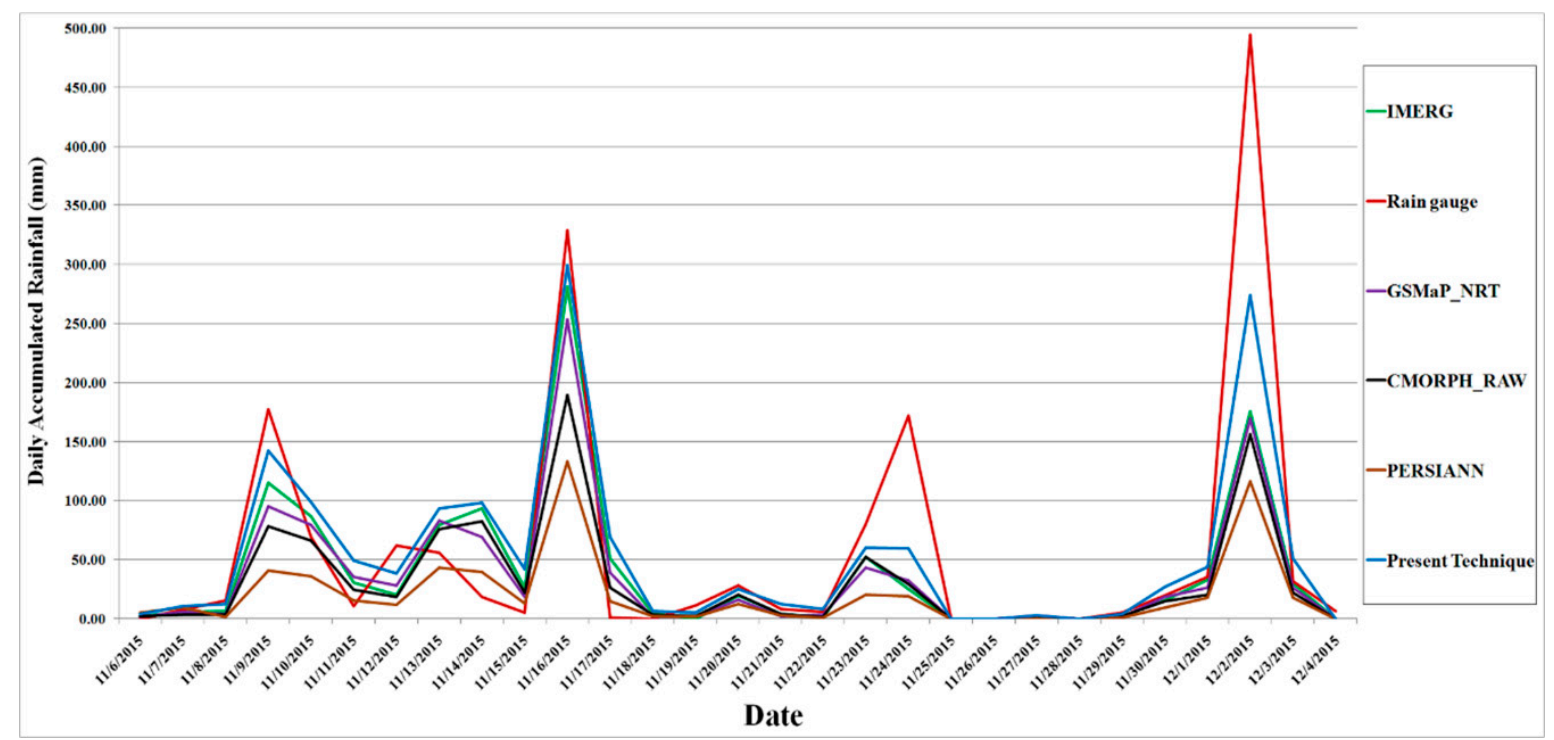

Figure 2. Rainfall over Tambram from rain gauge, IMERG, GSMaP, CMORPH, PERSIANN and the present technique for the floods of 2015.

\section{Conclusions}

The present study merged rainfall information from combined GMI-DPR and Meteosat observations by using the high accuracy of GMI-DPR based rainfall estimates and continuous Meteosat observations to monitor heavy precipitation. It offers an opportunity to explore the climatic aspect of heavy precipitation at a finer scale, since MFG has long past records. Studies suggest that being able to monitor extreme rainfall at a finer resolution would be sufficient to monitor flash floods $[1,2]$, . The present algorithm monitors near-real-time heavy rainfall, which is very crucial for nearreal-time flash flood monitoring. Mishra and Rafiq [23] used this technique to study heavy precipitation over the Indian region during the active phase of the south-west monsoon season. This is the first attempt to monitor near-real-time heavy precipitation over India through the synergistic use of multisatellite sensors from GPM and MFG. Past research reports that heavy precipitation events over the Indian region have changed as a result of warming [24,25]. These heavy precipitation events cause flood-like disasters. Recently, various parts of the Indian region experienced flood-like events [26-28]. The present technique can be very useful for the monitoring of near-real-time flash flood events, which can be helpful for mitigation and adaptation actions against flood-related disasters.

Acknowledgments: We acknowledge the funding for this work from the ISRO under grant No. B. 19012/174/2016-Sec.2. We are also grateful to CSIR for funding under grant no 24(0350)/17/EMR-II;Meteosat data from EUMETSET and the GPM data used in this study is also thankfully acknowledged.

Conflicts of Interest: There is no conflict of interest.

\section{References}

1. Mishra, A. A study on the occurrence of flood events over Jammu and Kashmir during September 2014 using satellite remote sensing. Nat. Hazards 2015, 78, 1463-1467.

2. Mishra, A.; Srinivasan, J. Did a cloud burst occur in Kedarnath during 16 and 17 June 2013. Curr. Sci. 2013, 105, 1351-1352.

3. Mishra, A.; Gairola, R.M.; Varma, A.K.; Agarwal, V.K. Remote sensing of Precipitation over Indian land and oceanic regions by synergistic use of multi-satellite sensors. J. Geophys. Res. 2010, 115, D08106, doi:10.1029/2009JD012157.

4. Huffman, G.J.; Adler, R.F.; Bolvin, D.T.; Gu, G.; Nelkin, E.J.; Bowman, K.P.; Hong, Y.; Stocker, E.F.; Wolff, D.B. The TRMM Multisatellite Precipitation Analysis (TMPA): Quasi-global, multiyear, combined-sensor precipitation estimates at fine scales. J. Hydrometeorol. 2007, 8, 38-55. 
5. Kubota, T.; Shige, S.; Hashizume, H.; Aonashi, A.; Takahashi, N.; Seto, S.; Hirose, M.; Takayabu, Y.N.; Ushio, T.; Nakagawa, K.; et al. Global precipitation map using satellite-borne microwave radiometers by the GSMaP project: Production and validation. IEEE Trans. Geosci. Remote Sens. 2007, 45, 2259-2275.

6. Aonashi, K.; Awaka, J.; Hirose, M.; Kozu, T.; Kubota, T.; Liu, G.; Shige, S.; Kida, S.; Seto, S.; Takahashi, N. et al. GSMaP passive microwave precipitation retrieval algorithm: Algorithm description and validation. J. Meteorol. Soc. Jpn. 2010, 87A, 119-136.

7. Joyce, R.J.; Janowiak, J.E.; Arkin, P.A.; Xie, P. CMORPH: A method that produces global precipitation estimates from passive microwave and infrared data at high spatial and temporal resolution. J. Hydrometeorol. 2004, 5, 487-503.

8. Hsu, K.L.; Gao, X.; Sorooshian, S.; Gupta, H.V. Precipitation estimation from remotely sensed information using artificial neural networks. J. Appl. Meteorol. Climatol. 1997, 36, 1176-1190.

9. Scofield, R.A.; Kuligowski, R.J. Status and outlook of operational satellite precipitation algorithms for extreme-precipitation events. Mon. Weather Rev. 2003, 18, 1037-1051.

10. Huffman, G.J.; Bolvin, D.T.; Braithwaite, D.; Su, K.H., Joyce, R.; Kidd, C.; Nelkin, E.J.; Xie, P. NASA Global Precipitation Measurement (GPM) Integrated Multi-satellitE Retrievals for GPM (IMERG), Algorithm Theoretical Basis Document (ATBD) Version 4.5; NASA: Washington, DC, USA, 2015; Available online: https://pmm.nasa.gov/sites/default/files/document_files/IMERG_ATBD_V4.5_0.pdf $\quad$ (accessed on 2 Feburary 2018).

11. Mishra, A.; Gairola, R.M.; Varma, A.K.; Sarkar, A.; Agarwal, V.K. Rainfall Retrieval over Indian land and oceanic regions from SSM/I Microwave data. Adv. Space Res. 2009, 44, 815-823.

12. Mishra, A.; Gairola, R.M.; Varma, A.K.; Agarwal, V.K. Study of Intense Heavy Rainfall Events over India Using KALPANA-IR and TRMM- Precipitation Radar Observations. Curr. Sci. 2009, 9, 689-695.

13. Mishra, A.; Gairola, R.M.; Agarwal, V.K. Rainfall Estimation from combined observations using KALPAANA-IR and TRMM-Precipitation Radar measurements over Indian Region. J. Indian Soc. Remote Sens. 2011, 40, 65-74.

14. Mishra, A.K. Monitoring Tamil Nadu flood of 2015 using satellite remote sensing. Nat. Hazards 2016, 82, 1431-1434.

15. Mishra, A.; Gairola, R.M.; Varma, A.K.; Agarwal, V.K. Improved rainfall estimation over Indian land oceanic regions using satellite infrared technique. Adv. Space Res. 2011, 48, 49-55.

16. Iguchi, T.; Kozu, T.; Kwiatkowski, J.; Meneghini, R.; Awaka, J.; Okamoto, K.I. Uncertainties in the Rain Profiling Algorithm for the TRMM Precipitation Radar. J. Meteorol. Soc. Jpn. 2009, 87, 1-30.

17. Grecu, M.; Olson, W.S.; Munchak, S.J.; Ringerud, S.; Liao, L.; Haddad, Z.; Kelley, B.L.; McLaughlin, S.F. The GPM Combined Algorithm. J. Atmos. Ocean. Technol. 2016, 33, 2225-2245.

18. Grecu, M.; Olson, W.S.; Shie, C.L.; L'Ecuyer, T.S.; Tao, W.K. Combining Satellite Microwave Radiometer and Radar observations to estimate atmospheric heating profiles. J. Clim. 2009, 22, 6356-6376.

19. Roca, R.; Viollier, M.; Picon, L.; Desbois, M. A multisatellite analysis of deep convection and its moist environment over the Indian Ocean during the winter monsoon. J. Geophys. Res. 2002, 107, INX2 11-1-INX2 $11-25$.

20. Rosenfeld, D.; Gutman, G. Retrieving microphysical properties near the tops of potential rain clouds by multispectral analysis of AVHRR data. Atmos. Res. 1994, 34, 259-283.

21. Adler, R.F.; Negri, A.J. A satellite infrared technique to estimate tropical convective and stratiform rainfall. J. Appl. Meteorol. 1988, 27, 30-51.

22. Laughlin, C.R. On the Effect of Temporal Sampling on the Observation of Mean Rainfall, Precipitation Measurements from Space; Work-Shop Report; Atlas, D., Thiele, O.W., Eds.; NASA/Goddard Space Flight Cent.: Greenbelt, MD, USA, 1981; pp. D59-D66.

23. Mishra, A.; Rafiq, M. Towards combining GPM and MFG observations to monitor near real time heavy precipitation at fine scale over India and nearby oceanic regions. Dyn. Atmos. Oceans 2017, 80, 62-74.

24. Goswami, B.N.; Venugopal, V.; Sengupta, D.; Madhusoodanan, M.S.; Xavier, P.K. Increasing trend of extreme rain events over India in a warming environment. Science 2006, 314, 1442-1445.

25. Mishra, A.; Liu, S.C. Changes in precipitation pattern and risk of drought over India in the context of global warming. J. Geophys. Res. Atmos. 2014, 119, 7833-7841.

26. Mishra, A. A new technique to estimate precipitation at fine scale using multifrequency satellite observations over Indian land and oceanic regions. IEEE Trans. Geosci. Remote Sens. 2013, 51, 4349-4358. 
27. Mishra, A.K. Estimation of heavy rainfall during cyclonic storms from microwave observations using nonlinear approach over Indian Ocean. Nat. Hazards 2012, 63, 673-683.

28. Rafiq, M.; Mishra, A.K. A study of heavy snowfall in Kashmir, India in January 2017. Weather 2018, 73, 1517.

(C) 2018 by the authors. Licensee MDPI, Basel, Switzerland. This article is an open access article distributed under the terms and conditions of the Creative Commons Attribution (CC BY) license (http://creativecommons.org/licenses/by/4.0/). 